\author{
Military Technical College \\ Kobry El-Kobbah, \\ Cairo, Egypt
}

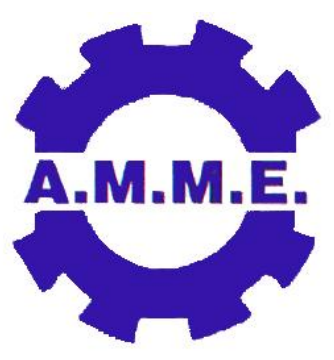

$14^{\text {th }}$ Internatinal Conference on Applied Mechanics and Mechanical Engineering.

\title{
MODELING AND ANALYSIS OF ISOTROPIC AND ANISOTROPIC TIEMOSHENKO BEAMS USING FINITE ELEMENT TECHNIQUE
}

By

M. R. Ajala** , M. Adnan Elshafei* and A. M. Riad ${ }^{\star}$

\begin{abstract}
In this paper, a finite element model has been proposed to analysis the response of isotropic and anisotropic beams subjected to different mechanical loads. The assumed field displacements of the beam are represented by simple first order deformation theory, the Timoshenko beam theory. The equation of motion is derived using the principle of virtual work. A hermit cubic shape function is used to represent the axial displacement $u$, the transverse displacement $w$ is represented by a quadratic shape function, whereas the normal rotation $\phi_{x}$ is represented by a linear shape function. The shear correction factor is used to improve the obtained results. A MATLAB code is constructed to compute the natural frequency, the static deformations, and the stresses on the structure due to the applied loads at different boundary conditions. The obtained results of the proposed model are compared to the available results of other investigators, good agreement is generally obtained.
\end{abstract}

KEY WORDS: Finite element methods - Timoshenko beam theory - composite materials mechanics - solid mechanics. 
* Egyptian Armed Forces.

** Libyan Armed Forces. 


\section{INTRODUCTION}

Several researchers are interested to solve the beam structures by different theories. Khdeir and Reddy [1] presented the solution of the governing equations for the bending of cross-ply laminated beams using the state-space concept in conjunction with the Jordan canonical form. They used the classical, the first-order, the second-order, and the thirdorder beam theories in their analysis. They determined the exact solutions for symmetric and asymmetric cross-ply laminated beams with arbitrary boundary conditions subjected to arbitrary loads. They studied the effect of shear deformation, number of layers, and the orthotropic ratio on the static response of composite beams. They found that the effect of shear deformation caused large differences between the predicted deflections by the classical beam theory and the higher order beam theories, especially when the ratio of beam length to its height was low. They also deduced that the symmetric cross-ply stacking sequence gave a smaller response than those of asymmetric ones. In case of asymmetric cross-ply arrangements, they noticed for the same beam thickness that the beam deflection decreased with increasing the number of beam layers and the orthotropic ratio, respectively.

Rao and Ganesan [2] investigated the harmonic response of tapered composite beams using a finite element model. They incorporated the uniaxial bending and Poisson's effect in their formulation. The effects of the in-plane and rotary inertia were considered in the mass matrix. They also investigated the influence of taper profile and taper parameter on the transversal displacement. For the taper profile effect, they predicted for any taper parameter and point harmonic load acting at one-quarter span that the transversal displacement obtained with increasing-decreasing thickness variation was lower than that of a uniform beam. For other thickness variation, the transversal displacement is higher than that of a uniform beam. For the taper parameter effect, they deduced that the frequency decreases with its increase in cases of increasing-decreasing thickness variations and vise-verse.

Yildirim, et al. [3] studied the in-plane free vibration problem of symmetric cross-ply laminated beams based on the transfer matrix method. They considered the rotary inertia, the shear, and the extensional deformation effects on the Timoshenko's beam analysis which gave good results compared to other reporters for the natural frequencies associated with the first and higher modes.

Nabi and Ganesan [4] studied the free vibration characteristics of laminated composite beams using a general finite element model based on a first-order deformation theory. The model accounted for bi-axial bending as well as torsion. Their obtained results explained the effect of shear-deformation on various vibration frequencies of angle ply laminates. Also, they studied the effect of beam geometry and boundary conditions on natural frequencies. They concluded that: (i) the natural frequencies decrease with the increase of fiber orientation angle, (ii) the non-dimensional frequency increases for all fiber orientations, with the increase of the beam length to height ratio, (iii) the clamped-free boundary conditions give the lowest natural frequency, and (iv) the shear deformations decrease the non-dimensional natural frequencies.

Elshafei, et al. [5,6] proposed a finite element model to study the static and the free vibration response of isotropic and anisotropic beams subjected to axial, bending, and torsion loads with warping effect using the classical beam theory. They found that an additional node in the middle of the beam element is required to give a better twisting 
deformation. The obtained results were in good agreement with FOBT and HOBT, respectively.

Armanios and Badir [7] evaluated analytically the effect of elastic coupling mechanisms on vibration behavior of thin-walled composite beams. Their analytical results were compared with those of the finite element models developed by Giavotto, et al. [8] and Hagodes, et al. [9], and the experimental measurements obtained by Chandra and Chopra [10]. Good agreement was obtained between their predictions and other predicted and experimental results of other investigators.

Chandrashekhara and Bangera [11] developed a finite element model based on a higherorder shear deformation theory with Poisson's effect, in-plane inertia and rotary inertia. They concluded that: (i) the shear deformations decrease the natural frequencies of the beam, (ii) the natural frequencies increase with the increase of the number of beam layers, (iii) the clamped-free boundary condition exhibits the lowest frequencies, (iv) the increase of fiber orientation angle decreases the natural frequency, and (v) the natural frequency decreases by increasing the material anisotropy.

In the present work, a finite element model has been proposed, based on Timoshenko beam theory with a shear correction factor, to predict the static and dynamic responses as well as the stress analysis of advanced isotropic and anisotropic beams. A MATLAB code is constructed to compute the structure response due to different applied loads at different boundary conditions.

\section{THEORETICAL FORMULATION}

The displacements field equations of the beam are assumed as [5]:

$$
u(x, z)=u_{\circ}(x)-z\left[c_{\circ} \frac{d w}{d x}+c_{1} \phi(x)\right]+c_{2} z^{2} \psi(x)+c_{3}(z / h)^{3}\left[\phi(x)+\frac{d w}{d x}\right],
$$

where

$$
v(x, z)=0,
$$

and

$$
w(x, z)=w_{0}(x) .
$$

$u, v$ and $w$ are the displacements field equations along the $x, y$ and $z$ coordinates, respectively, $u_{0}$ and $w_{0}$ denote the displacements of a point $(x, y, 0)$ at the mid plane, and $\phi(x)$ and $\psi(x)$ are the rotation angles of the cross-section as shown in Fig. 1. Selecting the constant values of Eqn. (1)a as: $c_{\circ}=0, \quad c_{1}=1, c_{2}=0, c_{3}=0$, the displacements field equations for Timoshenko first-order theory (FOBT) at any point through the thickness can be expressed as [12]:

$$
\begin{gathered}
u(x, z)=u_{\circ}(x)-z \phi(x) \\
v(x, z)=0 \\
w(x, z)=w_{0}(x)
\end{gathered}
$$

The strain-displacement relationships obtained by differentiating the assumed displacements field equation, Eqn. (2), are represented by: 


$$
\begin{gathered}
\varepsilon_{x x}(x, y, z) \equiv \frac{\partial u(x, y, z)}{\partial x}=\frac{\partial u_{\circ}(x, z)}{\partial x}-z \frac{\partial \phi_{x}(x, z)}{\partial x}=\varepsilon_{x x}^{\circ}+z \kappa_{x x}^{\circ} \\
\varepsilon_{y y}(x, y, z) \equiv \frac{\partial v(x, y, z)}{\partial y}=0 \\
\varepsilon_{z z}(x, y, z) \equiv \frac{\partial w(x, y, z)}{\partial z}=0 \\
\gamma_{\mathrm{xz}}(\mathrm{x}, \mathrm{y}, \mathrm{z}) \equiv \frac{\partial \mathrm{u}(\mathrm{x}, \mathrm{y}, \mathrm{z})}{\partial \mathrm{z}}+\frac{\partial \mathrm{w}(\mathrm{x}, \mathrm{y}, \mathrm{z})}{\partial \mathrm{x}}=-\phi_{\mathrm{x}}+\frac{\mathrm{dw}_{0}}{\mathrm{dx}}=\gamma_{\mathrm{xz}}^{\circ} \\
\gamma_{x y}(x, y, z) \equiv \frac{\partial v(x, y, z)}{\partial x}+\frac{\partial u(x, y, z)}{\partial y}=0 \\
\gamma_{\mathrm{yz}}(\mathrm{x}, \mathrm{y}, \mathrm{z}) \equiv \frac{\partial \mathrm{w}(\mathrm{x}, \mathrm{y}, \mathrm{z})}{\partial \mathrm{y}}+\frac{\partial \mathrm{v}(\mathrm{x}, \mathrm{y}, \mathrm{z})}{\partial \mathrm{z}}=0
\end{gathered}
$$

According to the assumptions of the first order Timoshenko beam theory $\left(\varepsilon_{y y}=\varepsilon_{z z}=\gamma_{x y}=\gamma_{y z}=0\right)$, the only non-zero stress and strain components are $\sigma_{x x}$, $\sigma_{x z}, \varepsilon_{x x}, \gamma_{x z}$ [13]. The strains at any point through the thickness of the beam can be written in matrix form as:

$$
\left\{\begin{array}{l}
\varepsilon_{x x} \\
\gamma_{x z}
\end{array}\right\}=\left\{\begin{array}{l}
\varepsilon_{x x}^{\circ} \\
\gamma_{x z}^{\circ}
\end{array}\right\}+z\left\{\begin{array}{l}
\kappa_{x x}^{\circ} \\
\kappa_{x z}^{\circ}
\end{array}\right\}
$$

where

$$
\begin{gathered}
\varepsilon_{x x}^{\circ}(x, z)=\frac{\partial u_{\circ}(x, z)}{\partial x} \\
\kappa_{x x}^{\circ}(x, z)=-\frac{\partial \phi_{X}}{\partial x}
\end{gathered}
$$

and

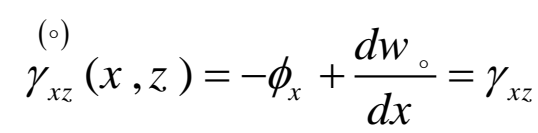

$\varepsilon_{x x}^{\circ}$ is the reference surface extensional strain in the x-direction, $\gamma_{x z}^{\circ}$ is the in-plane shear strain, and $\kappa_{x x}^{\circ}$ is the reference surface curvature in the x-direction.

\section{VARIATIONAL FORMULATION}

The equation of motion of the structure is derived herein using the principle of minimum potential energy. The total potential energy of the structure, $\Pi$, is represented by [14]:

$$
\Pi=U+W
$$

The internal strain energy for a beam element, $U$, is represented by [14]:

$$
U=\frac{1}{2} \iiint_{v}\left(\sigma_{x x} \varepsilon_{x x}+\sigma_{x z} \gamma_{x z}\right) d v .
$$




\section{Case I: Isotropic beam}

The stress-strain relation is given as [15]:

$$
\begin{aligned}
& \sigma_{x x}=\mathrm{E} \varepsilon_{x x} \\
& \sigma_{x z}=G \quad \gamma_{x z}=k_{s} G \quad \gamma_{x z}
\end{aligned}
$$

where $k_{s}$ is the shear correction factor.

Substituting by Eqn. (7) into Eqn. (6) results in:

$$
U=\frac{1}{2} \iiint_{V}\left(E\left(\varepsilon_{x x}\right)^{2}+k_{s} G\left(\gamma_{x z}\right)^{2}\right) d V
$$

By inserting Eqns. (3)a and (3)d into Eqn. (6), one can obtain:

$$
\begin{gathered}
U=\frac{1}{2} \iiint_{V}\left(E\left(\varepsilon_{x x}^{(0)}-z k_{x x}^{(0)}\right)^{2}+k_{s} G\left(-\phi_{x}+\frac{d w_{0}}{d x}\right)^{2}\right) d V \\
U=\frac{1}{2} \iiint_{V}\left\{E\left[\left(\left(\varepsilon_{x x}\right)^{2}-\left(2 z \varepsilon_{x x}^{(0)} k_{x x}^{(0)}\right)+\left(z k_{x x}^{(0)}\right)^{2}\right]+k_{s} G\left[\phi_{x}^{2}-2 \phi_{x} \frac{d w_{\circ}}{d x}+\left(\frac{d w_{0}}{d x}\right)^{2}\right]\right\} d V\right.
\end{gathered}
$$

Substituting by Eqn. (4)b into Eqn. (10)a, one can obtain:

$$
U=\frac{1}{2} \iiint_{V}\left\{E\left(\frac{d u_{\mathrm{o}}}{d x}\right)^{2}-2 z E\left[\left(\frac{d u_{\mathrm{o}}}{d x}\right)\left(\frac{d \phi}{d x}\right)\right]+z^{2} E\left(\frac{d \phi}{d x}\right)^{2}+k_{s} G\left[\phi_{x}^{2}-2 \phi_{x} \frac{d w_{\circ}}{d x}+\left(\frac{d w_{\mathrm{o}}}{d x}\right)^{2}\right]\right\} d V
$$

The variation of the strain energy term $U$, Eqn. (10)b is expressed as:

$$
\delta U=\frac{1}{2} \iiint_{v}\left[\begin{array}{c}
2 E\left[\sum_{j=1}^{4}\left(\frac{d u_{o j}}{d x}\right) \sum_{i=1}^{4}\left(\frac{\delta d u_{o i}}{d x}\right)\right] \\
-2 E z\left[\left[\sum_{j=1}^{2}\left(\frac{d \phi_{j}}{d x}\right) \sum_{i=1}^{4}\left(\frac{\delta d u_{o i}}{d x}\right)\right]+\left[\sum_{j=1}^{2}\left(\frac{d \phi_{j}}{d x}\right) \sum_{i=1}^{2}\left(\frac{d u_{o j}}{d x}\right) \sum_{i=1}^{2}\left(\frac{\delta d \phi_{i}}{d x}\right)\right]\right. \\
{\left[\left[\sum_{j=1}^{2}\left(\phi_{j}\right) \sum_{i=1}^{2}\left(\delta \phi_{i}\right)\right]-\left[\sum_{j=1}^{2}\left(\phi_{j}\right) \sum_{i=1}^{3}\left(\frac{\delta d w_{o i}}{d x}\right)\right]\right.} \\
2 k_{s} G\left[\begin{array}{l}
{\left[\sum_{j=1}^{3}\left(\frac{d w_{o j}}{d x}\right) \sum_{i=1}^{2}\left(\delta \phi_{i}\right)\right]+\left[\sum_{j=1}^{3}\left(\frac{d w_{o j}}{d x}\right) \sum_{i=1}^{3}\left(\frac{\delta d w_{o i}}{d x}\right)\right]}
\end{array}\right]
\end{array}\right] \cdot d v
$$

\section{Case II: Anisotropic Beam}

The stress-strain relation of a lamina in matrix notation is given in by $[13,16]$ :

$$
\left\{\begin{array}{l}
\sigma_{x x} \\
\sigma_{x z}
\end{array}\right\}=\left[\begin{array}{ll}
\tilde{Q}_{11} & \\
& \tilde{Q}_{55}
\end{array}\right]\left\{\begin{array}{l}
\varepsilon_{x x} \\
\varepsilon_{x z}
\end{array}\right\}
$$


The complete derivation of Eqn. (12) can be seen in Appendix A. Substituting by Eqn. (4) into Eqn. (12) yields the stress strain relation for the lamina as:

$$
\left\{\begin{array}{l}
\sigma_{x x} \\
\sigma_{x z}
\end{array}\right\}=\left[\begin{array}{cc}
\tilde{Q}_{11} & 0 \\
0 & \tilde{Q}_{55}
\end{array}\right]\left\{\begin{array}{c}
\varepsilon_{x x}^{\circ}+z k_{x x}^{\circ} \\
\gamma_{x z}^{\circ}
\end{array}\right\}
$$

The resultant forces and moments per unit length, $N_{x}$ and $M_{x}$, acting on a lamina are obtained by integrating the stresses in each layer through the lamina thickness as:

$$
\begin{gathered}
N_{x}=\int_{-h / 2}^{h / 2} \sigma_{x} d z=\sum_{n=1}^{N}\left[\int_{z_{k-1}}^{z_{k}}\left(\sigma_{x}\right)_{k} d z\right] \\
N_{x z}=\int_{-h / 2}^{h / 2} \sigma_{x z} d z=\sum_{n=1}^{N}\left[\int_{z_{k-1}}^{z_{k}}\left(\sigma_{x z}\right)_{k} d z\right] \\
M_{x}=\int_{-h / 2}^{h / 2} \sigma_{x} z d z=\sum_{n=1}^{N}\left[\int_{z_{k-1}}^{z_{k}}\left(\sigma_{x}\right)_{k} z d z\right] \\
M_{x z}=\int_{-h / 2}^{h / 2} \sigma_{x z} z d z=\sum_{n=1}^{N}\left[\int_{z_{k-1}}^{z_{k}}\left(\sigma_{x z}\right)_{k} z d z\right]
\end{gathered}
$$

Substituting by Eqn. (13) into Eqn. (14) and (15) yields:

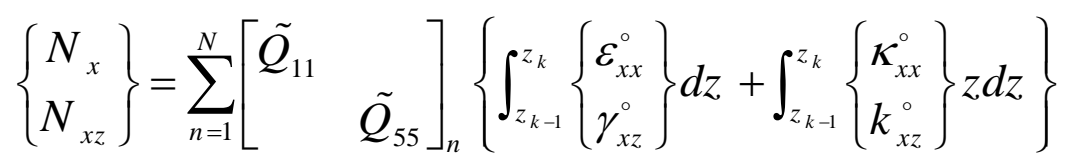

and

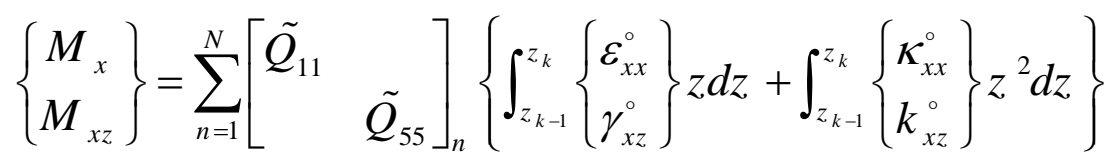

The mid-plane strain and curvatures are given in terms of forces and moments as [17]:

$$
\left[\begin{array}{l}
N \\
M
\end{array}\right]=\left[\begin{array}{ll}
A & B \\
B & D
\end{array}\right] \cdot\left[\begin{array}{c}
\varepsilon_{0} \\
\kappa^{0}
\end{array}\right]
$$

where $A_{i j}, B_{i j}$ and $D_{i j}$ represent the elements of the lamina extensional stiffness, coupling stiffness and bending stiffness matrices, respectively, and given by:

$$
\begin{gathered}
A_{i j}=\sum_{k=1}^{N}\left(\overline{Q_{i j}}\right)_{k} \cdot\left(z_{k}-z_{k-1}\right), \\
B_{i j}=\frac{1}{2} \sum_{k=1}^{N}\left(\overline{Q_{i j}}\right)_{k} \cdot\left(z_{k}^{2}-z_{k-1}^{2}\right), \text { and } \\
D_{i j}=\frac{1}{3} \sum_{k=1}^{N}\left(\overline{Q_{i j}}\right)_{k} \cdot\left(z_{k}^{3}-z_{k-1}^{3}\right) .
\end{gathered}
$$

Substituting by Eqn. (12) into Eqn. (13), then the internal strain energy of the composite beam is represented by: 


$$
U=\frac{1}{2} \iiint_{V}\left(\tilde{Q}_{11}\left(\varepsilon_{x x}\right)^{2}+k_{s} \tilde{Q}_{55}\left(\gamma_{x z}\right)^{2}\right) d V
$$

Substituting by Eqns. (3)a and (3)d into Eqn. (20), the internal strain energy of the beam is represented by:

$$
U=\frac{1}{2} \iiint_{V}\left(\tilde{Q}_{11}\left(\varepsilon_{x x}^{\circ}-z k_{x}^{\circ}\right)^{2}+k_{s} \tilde{Q}_{55}\left(-\phi_{x}+\frac{d w_{0}}{d x}\right)^{2}\right) d V
$$

or

$$
U=\frac{1}{2} \iiint_{V}\left\{\tilde{Q}_{11}\left[\left(\dot{\varepsilon}_{x}\right)^{2}-\left(2 z \dot{\varepsilon}_{x} \dot{k}_{x}^{0}\right)+\left(z k_{x}^{0}\right)^{2}\right]+k_{s} \tilde{Q}_{55}\left[\phi_{x}^{2}-2 \phi_{x} \frac{d w_{0}}{d x}+\left(\frac{d w_{0}}{d x}\right)^{2}\right]\right\} d V
$$

By performing the integration through the thickness, the internal strain energy for anisotropic beam in its final form is represented by:

$$
U=\frac{1}{2} \int_{-b / 2}^{b / 2} \int_{0}^{L}\left\{\begin{array}{l}
A_{11}\left[\left(\frac{d u_{\circ}}{d x}\right)^{2}\right]-2 B_{11}\left[\left(\frac{d u_{\circ}}{d x}\right)\left(\frac{d \phi_{x}}{d x}\right)\right]+D_{11}\left[\left(\frac{d \phi_{x}}{d x}\right)^{2}\right] \\
+k_{\mathrm{s}} A_{55}\left[\left(\phi_{x}\right)^{2}-2\left(\phi_{x} \frac{d w_{\circ}}{d x}\right)+\left(\frac{d w_{\circ}}{d x}\right)^{2}\right]
\end{array}\right\} d x d y
$$

By taking the variation of Eqn. (23), one can obtain:

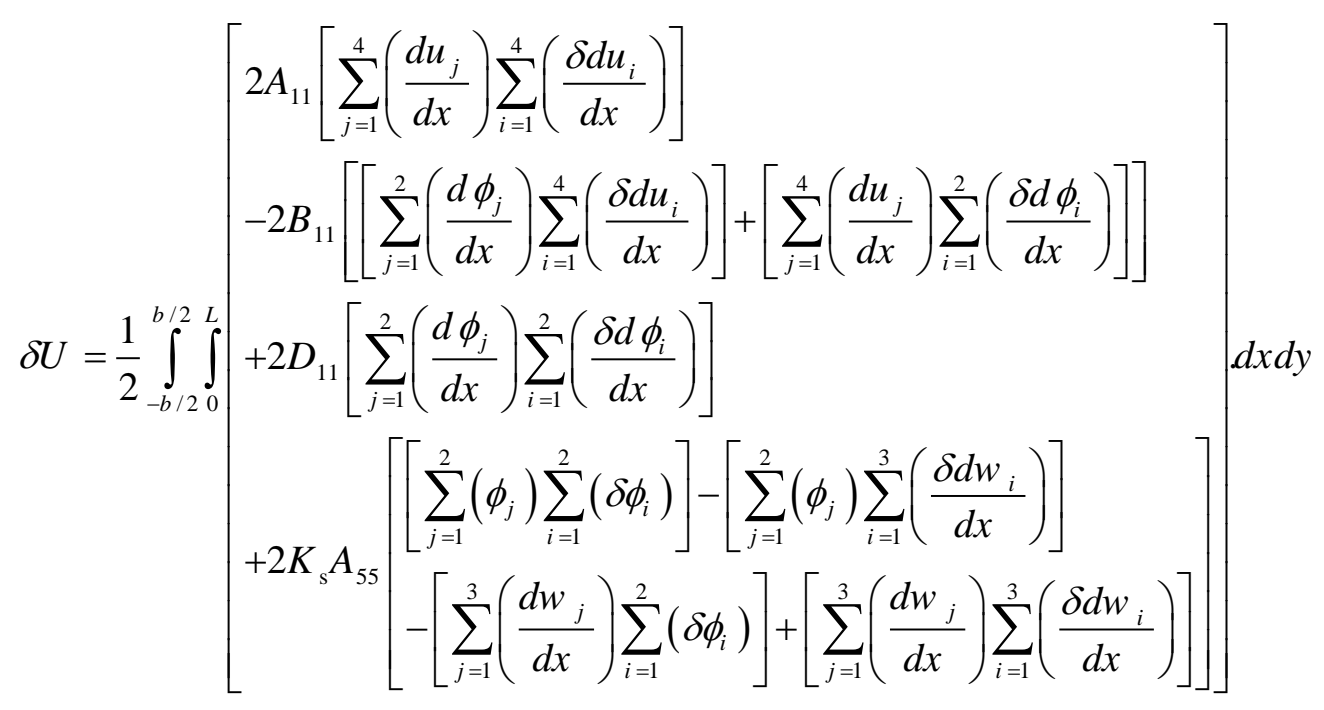

The work done due to external loads is represented by [4]:

$$
W=\iint_{R}\left[t u+f_{t} w\right] d x d y+\iint_{R}\left[f_{a} u\right] d y d z
$$

or

$$
W=\int_{-b / 2}^{b / 2} \int_{0}^{L}\left[(t \mathrm{u})+\left(f_{t} w\right)\right] d x d y+\int_{-h / 2-b / 2}^{h / 2} \int_{-b / 2}^{b / 2}\left[f_{a} u_{0}\right] d y d z
$$


where $(t)$ is the traction force along the surface, $\left(f_{t}\right)$ is the transversal forces, and $\left(f_{a}\right)$ is the axial forces. The first variation of Eqn. (26) yields:

$$
\delta W=\int_{-b / 2}^{b / 2} \int_{0}^{L}\left[t\left(\delta u_{\circ}-z \delta \phi_{x}\right)+\left(f_{t} \delta w\right)\right] d x d y+\int_{-h / 2}^{h / 2} \int_{-b / 2}^{b / 2}\left[f_{a} \delta u_{\circ}\right] d y d z
$$

\section{FINITE ELEMENT FORMULATION}

In formulating the finite element equations, two models are used. The first model is a simple one, which has two nodes for each element; each node has 6 degrees of freedom which representing the deformations $\mathrm{u}, \mathrm{w}$, and $\phi$. A linear shape function is used for each of them. In such a case, the predictions of the finite element model are not converged. In the second model, the element has 5 nodes with 9 degrees of freedom representing the deformations $\mathrm{u}, \mathrm{w}$, and $\phi$ as shown in the Fig. 2. The predictions of the finite element model in this case are converged and it is used for calculating the deflection and the natural frequency in the present work.

The axial displacement $u$ is expressed in the following form [18]:

$$
\frac{\partial^{4} u}{\partial x^{4}}=0
$$

By solving the previous equation and imposing the boundary conditions, the axial displacement can be represented as:

$$
u(x)=u_{1} \xi_{1}+u_{2} \xi_{2}+u_{3} \xi_{3}+u_{4} \xi_{4}=\sum_{j=1}^{4} u_{j} \xi_{j}
$$

The Hermit cubic shape functions $\xi_{j}$ are found to be:

$$
\begin{aligned}
\xi_{1}=1-3\left(\frac{x}{L}\right)^{2}+2\left(\frac{x}{L}\right)^{3}, & \xi_{2} & =\left(\frac{x}{L}\right)-2\left(\frac{x}{L}\right)^{2}+\left(\frac{x}{L}\right)^{3} \\
\xi_{3}=3\left(\frac{x}{L}\right)^{2}-2\left(\frac{x}{L}\right)^{3} & \xi_{4} & =-\left(\frac{x}{L}\right)^{3}-\left(\frac{x}{L}\right)^{2}
\end{aligned}
$$

The transversal displacement $w$ is represented as [19]:

$$
\frac{\partial^{3} w}{\partial x^{3}}=0
$$

By solving the above equation and apply the boundary conditions to determine the unknown constants, the transversal displacement ${ }^{w}$ can be expressed in terms of the nodal displacement as: 


$$
w(x)=w_{1} \zeta_{1}+w_{2} \zeta_{2}+w_{3} \zeta_{3}=\sum_{j=1}^{3} w_{j} \zeta_{j}
$$

where, the quadratic interpolation shape functions are given by:

$$
\zeta_{1}=1-3\left(\frac{x}{L}\right)+2\left(\frac{x}{L}\right)^{2} \quad \zeta_{2}=4\left(\frac{x}{L}\right)-4\left(\frac{x}{L}\right)^{2} \quad \zeta_{3}=-\left(\frac{x}{L}\right)+2\left(\frac{x}{L}\right)^{2}
$$

The rotation angle $\phi_{x}$ is expressed as [19]:

$$
\frac{\partial^{2} \phi_{x}}{\partial x^{2}}=0
$$

By solving Eqn. (34) and apply the boundary conditions, the rotation angle is given as:

$$
\phi(x)=\phi_{1} \psi_{1}+\phi_{2} \psi_{1}=\sum_{j=1}^{2} \phi_{j} \psi_{j}
$$

where the Linear interpolation shape functions $\psi_{j}$ have the form:

$$
\psi_{j}=1-\frac{X}{L}, \text { and } \quad \psi_{j}=\frac{X}{L} .
$$

\section{Case I: Isotropic beam:}

Substituting by Eqns. (29), (32) and (35) into Eqn. (11), one can obtain:

$$
\delta U=\frac{1}{2} \iint_{V}\left[\begin{array}{c}
2 E\left[\sum_{j=1}^{4}\left(\frac{d \xi_{j}}{d x}\right) \sum_{i=1}^{4}\left(\frac{\delta d \xi_{i}}{d x}\right)\right] \\
-2 E z\left[\left[\sum_{j=1}^{2}\left(\frac{d \psi_{j}}{d x}\right) \sum_{i=1}^{4}\left(\frac{\delta d \xi_{i}}{d x}\right)\right]+\left[\sum_{j=1}^{4}\left(\frac{d \xi_{j}}{d x}\right) \sum_{i=1}^{2}\left(\frac{\delta d \psi_{i}}{d x}\right)\right]\right] \\
\left.+2 \sum_{j=1}^{2}\left(\frac{d \psi_{j}}{d x}\right) \sum_{i=1}^{2}\left(\frac{\delta d \psi_{i}}{d x}\right)\right] \\
{\left[\left[\sum_{j=1}^{2}\left(\psi_{j}\right) \sum_{i=1}^{2}\left(\delta d \psi_{i}\right)\right]-\left[\sum_{j=1}^{2}\left(\psi_{j}\right) \sum_{i=1}^{3}\left(\frac{\delta d \zeta_{i}}{d x}\right)\right]\right.} \\
\left.-\left[\sum_{j=1}^{3}\left(\frac{d \zeta_{j}}{d x}\right) \sum_{i=1}^{2}\left(\delta \psi_{j}\right)\right]+\left[\sum_{j=1}^{3}\left(\frac{d \zeta_{j}}{d x}\right) \sum_{i=1}^{3}\left(\frac{\delta d \zeta_{i}}{d x}\right)\right]\right]
\end{array}\right] d V
$$

Equation (37) defines the element of stiffness matrix of the beam as:

$$
\begin{gathered}
K_{11}=E \iiint_{V}\left(\sum_{i=1}^{4}\left(\frac{d \xi_{i}}{d x}\right) \sum_{j=1}^{4}\left(\frac{d \xi_{j}}{d x}\right)\right) d V \\
K_{12}=K_{21}=0
\end{gathered}
$$




$$
\begin{gathered}
K_{13}=-\iiint_{V} E z\left(\sum_{i=1}^{4}\left(\frac{d \xi_{i}}{d x}\right) \sum_{j=1}^{2}\left(\frac{d \psi_{j}}{d x}\right)\right) d V \\
K_{22}=k_{s} G \iiint\left(\sum_{i=1}^{3}\left(\frac{d \zeta_{i}}{d x}\right) \sum_{j=1}^{3}\left(\frac{d \zeta_{j}}{d x}\right)\right) d V \\
K_{23}=-k_{s} G \iiint_{V}\left(\sum_{i=1}^{3}\left(\frac{d \zeta_{i}}{d x}\right) \sum_{j=1}^{2}\left(\psi_{j}\right)\right) d V \\
K_{31}=-\iiint_{V} E z\left(\sum_{i=1}^{2}\left(\frac{d \psi_{i}}{d x}\right) \sum_{j=1}^{4}\left(\frac{d \xi_{j}}{d x}\right)\right) d V \\
K_{32}=-k_{s} G \iiint_{V}\left(\sum_{i=1}^{2}\left(\psi_{i}\right) \sum_{j=1}^{3}\left(\frac{d \zeta_{j}}{d x}\right)\right) d V \\
K_{33}=\iiint_{V}\left(E z^{2}\left(\sum_{i=1}^{2}\left(\frac{d \psi_{i}}{d x}\right) \sum_{j=1}^{2}\left(\frac{d \psi_{j}}{d x}\right)\right)+k_{s} G\left(\sum_{i=1}^{2}\left(\psi_{i}\right) \sum_{j=1}^{2}\left(\psi_{j}\right)\right)\right) d V
\end{gathered}
$$

Substituting by Eqns. (30), (33) and (36) into Eqn. (38), and perform the integration, the element stiffness matrix for isotropic Timoshenko Beam is obtained, Cf. Appendix B.

\section{Case II: Anisotropic Beam:}

Substituting by Eqns. (29), (32) and (35) into Eqn. (24) yields:

$$
\delta U=\frac{1}{2} \iint\left[\begin{array}{c}
2 A_{11}\left[\sum_{j=1}^{4}\left(\frac{d \xi_{j}}{d x}\right) \sum_{i=1}^{4}\left(\frac{\delta d \xi_{i}}{d x}\right)\right] \\
-2 B_{11}\left[\left[\sum_{j=1}^{2}\left(\frac{d \psi_{j}}{d x}\right) \sum_{i=1}^{4}\left(\frac{\delta d \xi_{i}}{d x}\right)\right]+\left[\sum_{j=1}^{4}\left(\frac{d \xi_{i}}{d x}\right) \sum_{i=1}^{2}\left(\frac{\delta d \psi_{i}}{d x}\right)\right]\right] \\
\left.+\sum_{j=1}^{2}\left(\frac{d \psi_{j}}{d x}\right) \sum_{i=1}^{2}\left(\frac{\delta d \psi_{i}}{d x}\right)\right] \\
+2 K_{\mathrm{s}} A_{55}\left[\begin{array}{l}
{\left[\sum_{j=1}^{2}\left(\psi_{j}\right) \sum_{i=1}^{2}\left(\delta \psi_{i}\right)\right]-\left[\sum_{j=1}^{2}\left(\psi_{j}\right) \sum_{i=1}^{3}\left(\frac{\delta d \zeta_{i}}{d x}\right)\right]} \\
-\left[\sum_{j=1}^{3}\left(\frac{d \zeta_{j}}{d x}\right) \sum_{i=1}^{2}\left(\delta \psi_{i}\right)\right]+\left[\sum_{j=1}^{3}\left(\frac{d \zeta_{j}}{d x}\right) \sum_{i=1}^{3}\left(\frac{\delta d \zeta_{i}}{d x}\right)\right]
\end{array}\right]
\end{array}\right] . d x d y
$$

Rearranging Eqn. (39) gives:

$$
\begin{aligned}
& {\left[A _ { 1 1 } \{ \sum _ { i = 1 } ^ { 4 } \frac { d \xi _ { i } } { d x } \sum _ { j = 1 } ^ { 4 } \frac { d \xi _ { j } } { d x } \} u _ { j } \quad \left\{0 w_{j} \quad-B_{11}\left\{\sum_{i=1}^{4} \frac{d \xi_{j}}{d x} \sum_{j=1}^{2} \frac{d \psi_{j}}{d x}\right\} \phi_{j}\right.\right.}
\end{aligned}
$$

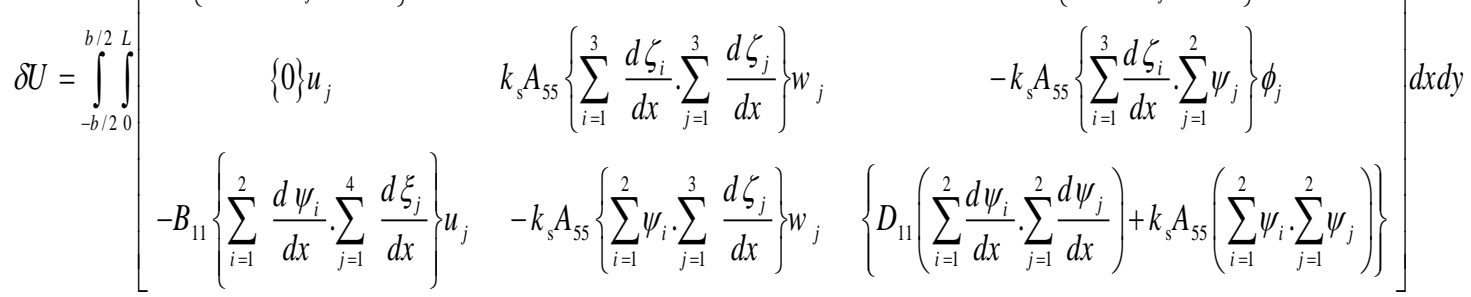


The element stiffness matrix can be deduced from equation (40) as:

$$
\begin{aligned}
& K_{11}=A_{11} \cdot \iint_{A}\left(\sum_{i=1}^{4}\left(\frac{d \xi_{i}}{d x}\right) \sum_{j=1}^{4}\left(\frac{d \xi_{j}}{d x}\right)\right) d x d y \\
& K_{12}=K_{21}=0 \\
& K_{13}=-B_{11} \iint_{A}\left(\sum_{i=1}^{4}\left(\frac{d \xi_{i}}{d x}\right) \sum_{j=1}^{2}\left(\frac{d \psi_{j}}{d x}\right)\right) d x d y \\
& K_{22}=k_{\mathrm{s}} A_{55} \iint_{A}\left(\sum_{i=1}^{3}\left(\frac{d \zeta_{i}}{d x}\right) \sum_{j=1}^{3}\left(\frac{d \zeta_{j}}{d x}\right)\right) d x d y \\
& K_{23}=-k_{\mathrm{s}} A_{55} \iint_{A}\left(\sum_{i=1}^{3}\left(\frac{d \zeta_{i}}{d x}\right) \sum_{j=1}^{2}\left(\psi_{j}\right)\right) d x d y \\
& K_{31}=-B_{11} \iint_{A}\left(\sum_{i=1}^{2}\left(\frac{d \psi_{i}}{d x}\right) \sum_{j=1}^{4}\left(\frac{d \xi_{j}}{d x}\right)\right) d x d y \\
& K_{32}=-k_{\mathrm{s}} A_{55} \iint_{A}\left(\sum_{i=1}^{2}\left(\psi_{i}\right) \sum_{j=1}^{3}\left(\frac{d \zeta_{j}}{d x}\right)\right) d x d y \\
& K_{33}=\iint_{A}\left(D_{11} \sum_{i=1}^{2}\left(\frac{d \psi_{i}}{d x}\right) \sum_{j=1}^{2}\left(\frac{d \psi_{j}}{d x}\right)+k_{\mathrm{s}} A_{55} \sum_{i=1}^{2}\left(\psi_{i}\right) \sum_{j=1}^{2}\left(\psi_{j}\right)\right) d x d y
\end{aligned}
$$

Substituting by Eqns. (30), (33) and (36) into Eqn. (41) and perform the integration, the element stiffness matrix of anisotropic beam element is obtained, Cf. Appendix B.

The consistent mass matrix for a beam element in stretching and bending can be obtained using the kinetic energy equation as follows:

$$
T=\frac{1}{2} \rho \iiint_{V}\left[\dot{u}^{2}+\dot{w}^{2}\right] d V
$$

where $\rho$ is the material mass density. The first variation of Eqn. (42) yields:

$$
\delta T=\frac{1}{2} \rho \iiint_{V} 2[u \delta u+\mathrm{w} \delta w] \cdot d V
$$

Substituting by Eqn. (2) into Eqn. (43) yields:

$$
\delta T=\rho \iiint_{V}\left[\left(u_{\circ} \delta u_{\circ}\right)-z\left(\phi_{x} \delta u_{\circ}\right)-z\left(u_{\circ} \delta \phi_{x}\right)+z^{2}\left(\phi_{x} \delta \phi_{x}\right)+\left(w_{\circ} \delta w_{\circ}\right)\right] d V .
$$

The element mass matrix can be obtained from Eqn. (44) as:

$$
M_{11}=I_{\circ} \int_{0}^{L}\left(u_{\circ} \delta u_{\circ}\right) d x
$$




$$
\begin{gathered}
M_{12}=M_{21}=0 \\
M_{13}=-I_{1} \int_{0}^{L}\left(\phi_{x} \delta u_{\circ}\right) d x \\
M_{22}=I_{\circ} \int_{0}^{L}\left(w_{\circ} \delta w_{\circ}\right) \cdot d x \\
M_{23}=M_{32}=0 \\
M_{31}=-I_{1} \int_{0}^{L}\left(u_{\circ} \delta \phi_{x}\right) d x \\
M_{33}=I_{2} \int_{0}^{L}\left(\phi_{x} \delta \phi_{x}\right) d x
\end{gathered}
$$

where $\left(I_{\circ}, I_{1}, I_{2}\right)=\rho \int_{A}\left(1, z, z^{2}\right) d A$ and $/$ is the moment of inertia.

Substituting by Eqns. (29), (30), (32), (33), (35) and (36) into equation (45) and perform the integrating, the element mass matrix is obtained, Cf. Appendix B. The element load vector can be obtained by substituting the shape functions Eqns. (29), (32) and (35) into Eqn. (27), which yields:

$$
\begin{aligned}
\delta W= & \iint_{A}\left[\xi_{j} t\right] \delta u_{i} d x d y+\iint_{A}\left[\xi_{j} f_{a}\right] \delta u_{i} d y d z \\
& -\iint_{A}\left[z \psi_{j} t\right] \cdot \delta \phi_{i} d x d y+\iint_{A}\left[\zeta_{j} f_{t}\right] \delta w_{i} d x d y
\end{aligned}
$$

From equation (46), the elements of the load vector are:

$$
\begin{gathered}
F_{1}(1,1)=\int_{-b / 2}^{b / 2} \int_{0}^{L}\left[t \xi_{1}\right] d x d y+\int_{-h / 2}^{h / 2} \int_{-b / 2}^{b / 2}\left[f a \xi_{1}\right] d y d z \\
F_{1}(2,1)=\int_{-b / 2}^{b / 2} \int_{0}^{L}\left[t \xi_{2}\right] d x d y+\int_{-h / 2}^{h / 2} \int_{-b / 2}^{b / 2}\left[f a \xi_{2}\right] d y d z \\
F_{1}(3,1)=\int_{-b / 2}^{b / 2} \int_{0}^{L}\left[t \xi_{3}\right] d x d y+\int_{-h / 2}^{b / 2} \int_{-b / 2}^{h / 2}\left[f a \xi_{3}\right] d y d z \\
F_{1}(4,1)=\int_{-b / 2}^{b / 2} \int_{0}^{L}\left[t \xi_{4}\right] d x d y+\int_{-h / 2}^{b / 2}\left[f a \xi_{4}\right] d y d z \\
F_{2}(1,1)=\int_{-b / 2}^{b / 2} \int_{0}^{L}\left[f t \zeta_{1}\right] d x d y \\
F_{2}(2,1)=\int_{-b / 2}^{b / 2} \int_{0}^{L}\left[f t \zeta_{2}\right] d x d y \\
F_{3}(1,1)=\int_{-b / 2}^{L} \int_{-b / 2}^{b / 2}\left[f t \zeta_{0}^{L}\left[t z z \psi_{1}\right] d x d y\right.
\end{gathered}
$$




$$
F_{3}(2,1)=\int_{-b / 2}^{b / 2} \int_{0}^{L}\left[t \quad z \psi_{2}\right] d x d y
$$

Substituting by Eqns. (30), (33) and (36) into Eqn. (46) and perform the integrating, the element load vector can be obtained, Cf. Appendix B.

\section{Equation of Motion}

The system equation of motion is given in matrix form as [2]:

$$
[M]\{\ddot{q}\}+[K]\{q\}=\{F\}
$$

where $[M]$ is the global mass matrix, $\{\ddot{q}\}$ is the second derivative of the nodal displacements with respect to time, $[K]$ is the global stiffness matrix, $\{q\}$ is the nodal displacements vector and $\{F\}$ is the global nodal forces vector.

\section{Numerical Examples}

A MATLAB code is constructed to perform the analysis of isotropic and anisotropic beams using the present finite element model. The static and free vibration analyses are preformed for beams subjected to different kinds of mechanical loads. The model inputs are the beam dimensions (length, width and height), material specifications (Young's modulus, material mass density) and number of beam layers and its elements. The present model is capable of predicting the nodal (axial and transversal) deflections, normal and shear stresses and the fundamental natural frequency of the beam, respectively.

\section{Case I: Isotropic beam results}

\section{a) Model validation}

The validation of the present model and its results convergence are checked for the isotropic beam element with the material properties shown in Table (1). The obtained results are shown in Fig. 3, which presents the effect of number of element on the transversal tip deflection of a cantilever beam, with length to height ratio of 10 , subjected to uniform distributed loads. It can be seen from the figure that the model predictions are converge at number of elements of 8 .

\section{b) Static analysis}

Another example of an isotropic beam with simply supported boundary condition subjected to uniform distributed loads is presented. The input data to the finite element model are listed in Table 2.

The predicted results of the model are listed in Table 3 and Fig. 4 for the maximum transversal deflection of isotropic beam subjected to a uniformly distributed load with simply supported boundary condition at its ends when using a shear correction factor $\mathrm{k}$ $=5 / 6$. These results are compared to the exact solution of Ref. [12] which are plotted on the same figure. 
Table 4 shows the comparison of the maximum deflection of a clamped-clamped beam under uniformly distributed load. It can be seen that the model gave good results compared to the exact solution given by Ref. [12].

\section{Case II: Anisotropic Beam results}

\section{a) Static Analysis}

To check the validity of the anisotropic model and to establish its range of applicability, a numerical example is investigated and the obtained results are compared to the published results for the same example. For a cantilever beam presented by Ref. [20], its predicted mid span displacements are compared with the predictions of the present model. Results are reported with the following dimensionless material properties, $E_{1} / E_{2}=25$, $G_{12}=0.5 E_{2}$ and $v_{12}=0.25$. The beam is considered to have different length to height ratio, $(L / h=5,10,50)$, and is subjected to a uniformly distributed load with intensity of 10 $(\mathrm{kN} / \mathrm{m})$. The beam is solved considering different fiber orientation angles

Table 1. Material properties for aluminum isotropic beam.

\begin{tabular}{|c|c|c|}
\hline Property & Aluminum & Unit \\
\hline$E$ & 68.9 & $\mathrm{GPa}$ \\
\hline$v$ & 0.25 & - \\
\hline $\mathrm{G}$ & 27.6 & $\mathrm{GPa}$ \\
\hline$\rho$ & 2769 & $\left(\mathrm{~kg} / \mathrm{m}^{3}\right)$ \\
\hline Length, $\mathrm{L}$ & 0.1524 & $(\mathrm{~m})$ \\
\hline Width, $\mathrm{b}$ & 0.0254 & $(\mathrm{~m})$ \\
\hline Height, $\mathrm{h}$ & 0.01524 & $(\mathrm{~m})$ \\
\hline
\end{tabular}

Table 2. Material properties for steel isotropic beam.

\begin{tabular}{|c|c|c|}
\hline Property & Steel & Unit \\
\hline$E$ & $30 \times 106$ & psi \\
\hline$v$ & 0.36 & - \\
\hline$G$ & $11 \times 106$ & psi \\
\hline$\rho$ & 0.281 & (lb/in3) \\
\hline Length, $\mathrm{L}$ & 100 & (in) \\
\hline Width, b & 1 & (in) \\
\hline Height, $\mathrm{h}$ & 1 & (in) \\
\hline
\end{tabular}


Table 3. Finite element results for the maximum deflection at mid span of simply supported beam under uniformly distributed load $(L / h=100)$.

\begin{tabular}{|c|c|c|}
\hline \multirow{2}{*}{ Load (lb/in) } & \multicolumn{2}{|c|}{ Maximum deflection of simply supported beam, [in] } \\
\cline { 2 - 3 } & Ref. [12] (8-element) & $\begin{array}{c}\text { Present model (8- } \\
\text { element) }\end{array}$ \\
\hline 1.0 & 0.5208 & 0.5144 \\
\hline 2.0 & 1.0417 & 1.0289 \\
\hline 3.0 & 1.5625 & 1.5433 \\
\hline 4.0 & 2.0833 & 2.0577 \\
\hline 5.0 & 2.6042 & 2.5721 \\
\hline 6.0 & 3.1250 & 3.0866 \\
\hline 7.0 & 3.6458 & 3.6010 \\
\hline 8.0 & 4.1667 & 4.1154 \\
\hline 9.0 & 4.6875 & 4.6298 \\
\hline 10.0 & 5.2083 & 5.1443 \\
\hline
\end{tabular}

Table 4. Finite element results for the maximum deflection at mid span of a clampedclamped beam under uniformly distributed load $(\mathrm{L} / \mathrm{h}=100)$.

\begin{tabular}{|c|c|c|}
\hline \multirow{2}{*}{ Load (lb/in) } & \multicolumn{2}{|c|}{$\begin{array}{c}\text { Maximum deflection of a clamped-clamped beam, } \\
\text { [in] }\end{array}$} \\
\cline { 2 - 3 } & Ref. [12] (8-element) & $\begin{array}{c}\text { Present model (8- } \\
\text { element) }\end{array}$ \\
\hline 1.0 & 0.1034 & 0.0978 \\
\hline 2.0 & 0.2023 & 0.1955 \\
\hline 3.0 & 0.2939 & 0.2933 \\
\hline 4.0 & 0.3774 & 0.3910 \\
\hline 5.0 & 0.4530 & 0.4888 \\
\hline 6.0 & 0.5216 & 0.5866 \\
\hline 7.0 & 0.5841 & 0.6843 \\
\hline 8.0 & 0.6414 & 0.7821 \\
\hline 9.0 & 0.6943 & 0.8798 \\
\hline 10.0 & 0.7433 & 0.9771 \\
\hline
\end{tabular}

for the case of symmetric cross-ply $\left(0^{\circ}, 90^{\circ}, 0^{\circ}\right)$ and asymmetric cross-ply $\left(0^{\circ}, 90^{\circ}\right)$. Each lamina is assumed to have the same thickness and made of the same material. The nondimensional transversal deflection is determined by: $\bar{w}=\frac{W A E_{2} h^{2} 10^{2}}{f_{0} L^{4}}$; where $(w)$ is the actual transversal deflection and $\left(f_{\mathrm{o}}\right)$ is the uniformly distributed load. For the case of symmetric cross-ply $\left(0^{\circ}, 90^{\circ}, 0^{\circ}\right)$ and asymmetric cross-ply $\left(0^{\circ}, 90^{\circ}\right)$ laminations, the static results are presented in Tables 5, 6 and 7 in comparison to the results obtained by Khdier 
and Reddy [1]. It is clear from the tables that the obtained results by the present model is better for beams having small aspect ratios and close to the predictions of FOBT theory.

Figure 5 compares between the transversal deflection of the beam with the results obtained in Ref. [20]. The present figure shows the effect of number of layers on the nondimensional transversal deflection of the beam. It is seen that the beam stiffness increases and consequently the non-dimensional transversal deflection decreases as the number of layers increases.

\section{b) Stress Analysis}

In the following, the normal and shear stresses distributions of a composite beam having $E_{1} / E_{2}=25, G_{12}=0.5 E_{2}$ and $v_{12}=0.25,(L / h=10)$, and subjected to a uniformly distributed load with intensity $(1 \mathrm{~N} / \mathrm{m})$ are predicted using the present model. Figure 6 and Fig. 7 show the normal stress distribution for a symmetric cross ply composite laminate with fibers orientation angles of $\left(0^{\circ} / 90^{\circ} / 90^{\circ} / 0^{\circ}\right)$ and an asymmetric cross ply laminate with fiber orientation angles of $\left(0^{\circ} / 45^{\circ} /-45^{\circ} /, 90^{\circ} / 90^{\circ} /-45^{\circ} / 45^{\circ} / 0^{\circ}\right)$, respectively. In addition, Figure 8 shows the shear stress for a symmetric cross-ply composite laminate with fibers orientation angles of $\left(0^{\circ} / 90^{\circ} / 90^{\circ} / 0^{\circ}\right)$.

Table 5. Non-dimensional mid-span deflection of symmetric cross-ply $\left(0^{\circ}, 90^{\circ}, 0^{\circ}\right)$ Laminated cantilever beams.

\begin{tabular}{|c|c|c|c|c|c|}
\hline \multirow{2}{*}{ L/h } & \multicolumn{5}{|c|}{ Non-dimensional mid-span deflection of cantilever beams } \\
\cline { 2 - 6 } & HOBT [1] & SOBT [1] & $\begin{array}{c}\text { FOBT } \\
\text { [1] }\end{array}$ & CBT [1] & Present model \\
\hline 5 & 6.824 & 5.948 & 6.698 & 2.198 & 6.6364 \\
\hline 10 & 3.455 & 3.135 & 3.323 & 2.198 & 3.3994 \\
\hline 50 & 2.251 & 2.235 & 2.243 & 2.198 & 2.3636 \\
\hline
\end{tabular}

Table 6. Non-dimensional mid-span deflection of symmetric cross-ply $\left(0^{\circ}, 90^{\circ}, 0^{\circ}\right)$ laminated clamped-clamped beams.

\begin{tabular}{|c|c|c|c|}
\hline $\begin{array}{c}\text { Beam } \\
\text { laminate } \\
\text { orientati } \\
\text { on }\end{array}$ & L/h & \multicolumn{2}{|c|}{ Non-dimensional mid-span deflection of C-C beams } \\
\cline { 2 - 4 } & FOBT [1] & Present Model \\
\hline \multirow{2}{*}{$(0 / 90 / 0)$} & 5 & 1.537 & 1.5740 \\
\cline { 2 - 4 } & 10 & 0.532 & 0.4950 \\
\cline { 2 - 4 } & 50 & 0.147 & 0.1498 \\
\hline \multirow{3}{*}{$(0 / 90)$} & 5 & 1.922 & 2.4357 \\
\cline { 2 - 4 } & 10 & 1.005 & 1.1169 \\
\cline { 2 - 4 } & 50 & 0.679 & 0.6948 \\
\hline
\end{tabular}


Table 7. Non-dimensional mid-span deflection of symmetric $\left(0^{\circ}, 90^{\circ}\right)$ laminated cantilever beams.

\begin{tabular}{|c|c|c|c|c|c|}
\hline \multirow{2}{*}{$L / h$} & \multicolumn{5}{|c|}{ Non-dimensional mid-span deflection of cantilever beams } \\
\cline { 2 - 6 } & HOBT [1] & SOBT [1] & FOBT [1] & CBT [1] & $\begin{array}{c}\text { Present } \\
\text { model }\end{array}$ \\
\hline 5 & 15.279 & 15.695 & 16.436 & 11.293 & 17.198 \\
\hline 10 & 12.343 & 12.400 & 12.579 & 11.293 & 13.242 \\
\hline 50 & 11.337 & 11.338 & 11.345 & 11.293 & 11.976 \\
\hline
\end{tabular}

\section{c) Free vibration Analysis}

The predicted values of the fundamental natural frequency are compared with that of Ref. [11] for a composite cantilever beam. The beam properties are: $E_{1}=144.80 \mathrm{GPa}$, $E_{2}=9.65 \mathrm{GPa}, G_{12}=4.14 \mathrm{GPa}, v_{12}=0.3$, and $\rho=1389.23 \mathrm{Kg} / \mathrm{m}^{3}$. The beam length to height ratio is $L / h=15$. The non-dimensional fundamental natural frequency is calculated by: $\bar{\omega}=\omega L^{2} \sqrt{\left(\rho / E_{1} h^{2}\right)}$, where $\omega$ and $\rho$ are the free natural frequency and material density of the beam, respectively. For the symmetrically laminates with orientation angles of [0/90/90/0], and [45/-45/-45/45], Table 8 shows that the obtained results of the present model are agreed with the results of the higher order shear deformation theory (HSDT) [11].

Table 9 shows the effect of number of layers on the non-dimensional natural frequencies of symmetrical laminated beams with clamped-free edges obtained by the present model and the corresponding predicted results of Ref. [11]; good agreement is generally obtained. It is also seen from the table that the predictive capability of the model is improved with increasing the number of layers. In addition, Table 10 shows the predicted effect of ply orientation angles on the non-dimensional natural frequencies of clampedclamped beams of the present model and the corresponding predictions of Ref. [11]. Good agreement is obtained for ply orientations of [ 0/90/90/0 ] and [ 45/-45/-45/45] till the third mode. For higher modes, further work is needed to improve the predictive capabilities of the model.

Table 11 shows the effect of different boundary conditions of asymmetric laminated beams on their non-dimensional natural frequencies predicted by the present model and the corresponding predictions of Ref. [11]. The listed results recommend further work to improve the model predictions. 
Table 8. Non-dimensional natural frequencies of symmetrically laminated beams under various boundary conditions at $(\mathrm{NE}=80)$.

\begin{tabular}{|c|c|c|c|c|}
\hline Parameter & \multicolumn{4}{|c|}{ Non-dimensional natural frequencies. } \\
\hline $\begin{array}{c}\text { Ply } \\
\text { orientation }\end{array}$ & \multicolumn{2}{|c|}{$[0 / 90 / 90 / 0$ ] } & \multicolumn{2}{c|}{ [ 45/-45/-45/45 ] } \\
\hline $\begin{array}{c}\text { Boundary } \\
\text { Conditions }\end{array}$ & Ref. [11] & $\begin{array}{c}\text { Present } \\
\text { model }\end{array}$ & Ref. [11] & $\begin{array}{c}\text { Present } \\
\text { model }\end{array}$ \\
\hline S - S & 2.5023 & 2.5236 & 0.8295 & 0.9096 \\
\hline C - C & 4.5940 & 4.7619 & 1.8472 & 2.0054 \\
\hline C - S & 3.5254 & 3.6078 & 1.2855 & 1.4033 \\
\hline C - F & 0.9241 & 0.9268 & 0.2965 & 0.3256 \\
\hline
\end{tabular}

Table 9. The effect of number of layers on the non-dimensional natural frequencies of angle-ply and cross-ply laminated beams with clamped-free edges. (NE=80).

\begin{tabular}{|c|c|c|c|c|}
\hline Parameter & \multicolumn{4}{|c|}{ Non-dimensional natural frequencies. } \\
\hline $\begin{array}{c}\text { Ply } \\
\text { orientation }\end{array}$ & \multicolumn{2}{|c|}{$[\mathbf{4 5 / - 4 5 / 4 5 / \ldots ]}$} & \multicolumn{2}{c|}{ [0/90/0/..] } \\
\hline No. of layers & Ref. [11] & $\begin{array}{c}\text { Present } \\
\text { model }\end{array}$ & Ref. [11] & $\begin{array}{c}\text { Present } \\
\text { model }\end{array}$ \\
\hline 2 & 0.3031 & 0.3254 & 0.4800 & 0.4750 \\
\hline 4 & 0.3223 & 0.3254 & 0.6748 & 0.6735 \\
\hline 6 & 0.3242 & 0.3254 & 0.7047 & 0.7042 \\
\hline 8 & 0.3247 & 0.3254 & 0.7148 & 0.7147 \\
\hline 10 & 0.3249 & 0.3254 & 0.7195 & 0.71953 \\
\hline
\end{tabular}

Table 10. The effect of ply orientation angle on the non-dimensional natural frequencies of clamped-clamped beams $(\mathrm{NE}=80)$.

\begin{tabular}{|c|c|c|c|c|c|c|}
\hline $\begin{array}{c}\text { Paramete } \\
\mathbf{r}\end{array}$ & \multicolumn{2}{|c|}{ Non-dimensional natural frequencies of clamped-clamped beams. } \\
\hline $\begin{array}{c}\text { Ply } \\
\text { orientatio } \\
\mathbf{n}\end{array}$ & \multicolumn{2}{|c|}{$[\mathbf{0 / 9 0 / 0 / 9 0 ]}$} & \multicolumn{2}{|c|}{ [ 45/-45/45/-45 ] } & \multicolumn{2}{|c|}{ [ 30/50/30/50 ] } \\
\hline Mode No. & Ref. [11] & $\begin{array}{c}\text { Present } \\
\text { model }\end{array}$ & Ref. [11] & $\begin{array}{c}\text { Present } \\
\text { model }\end{array}$ & Ref. [11] & $\begin{array}{c}\text { Present } \\
\text { model }\end{array}$ \\
\hline 1 & 3.7244 & 3.7951 & 1.9807 & 2.0054 & 2.2526 & 2.6180 \\
\hline 2 & 8.9275 & 9.1776 & 5.2165 & 5.2926 & 5.8624 & 6.7417 \\
\hline 3 & 15.3408 & 15.8238 & 9.6912 & 9.8504 & 10.7609 & 12.2361 \\
\hline 4 & 22.3940 & 23.1233 & 10.5345 & 15.2896 & 11.9506 & 18.5929 \\
\hline 5 & 24.3155 & 30.7024 & 15.0981 & 15.2912 & 16.5747 & 21.0844 \\
\hline
\end{tabular}


Table 11. Non-dimensional natural frequencies of anti-symmetric laminated beam with plies angles [45/-45/45/-45] with various boundary conditions (NE=80).

\begin{tabular}{|c|c|c|c|c|c|c|}
\hline \multirow{2}{*}{ Parameter } & \multicolumn{6}{|c|}{$\begin{array}{c}\text { Non-dimensional natural frequencies of anti-symmetric laminated } \\
\text { beam with plies angles [45/-45/45/-45] }\end{array}$} \\
\hline Beam type & \multicolumn{2}{|c|}{ C-F } & \multicolumn{2}{c|}{ S-S } & \multicolumn{2}{c|}{ C-C } \\
\hline Mode No. & Ref. [11] & $\begin{array}{c}\text { Present } \\
\text { model }\end{array}$ & Ref. [11] & $\begin{array}{c}\text { Present } \\
\text { model }\end{array}$ & Ref. [11] & $\begin{array}{c}\text { Present } \\
\text { model }\end{array}$ \\
\hline 1 & 0.2962 & 0.3256 & 0.8278 & 0.9096 & 1.8298 & 2.0054 \\
\hline 2 & 1.8156 & 1.9910 & 3.2334 & 3.5469 & 4.8472 & 5.2926 \\
\hline 3 & 4.9163 & 5.3752 & 7.0148 & 7.6747 & 9.0601 & 9.8504 \\
\hline 4 & 5.3660 & 10.0384 & 10.7449 & 12.9927 & 10.7449 & 15.2896 \\
\hline 5 & 9.2162 & 15.2896 & 11.9145 & 15.2896 & 14.1999 & 15.2912 \\
\hline
\end{tabular}

\section{CONCLUSIONS}

The following conclusions have been drawn:

1. The good agreement between the mid-span deflections predicted by the present model and the corresponding predictions of other investigators using FOBT, SOBT, and HOBT theories proves the predictive capabilities of such a model.

2. The transversal displacements predicted by the present finite element model are found to converge towards an asymptote at reasonable number of elements.

3. As the number of layers increases, the transversal deflection decreases and the accuracy of the present model for the natural frequencies increases.

4. The inclusion of shear correction factor in the present model may improve its predictions.

5. Further work is needed to improve the predictive capabilities of the present model by covering the following:

(a) Using the first order shear deformation theory, SOBT, to include the transversal shear effects, and

(b) Taking into account the geometric nonlinearities.

\section{REFERENCES}

[1] A.A. Khdeir and J.N. Reddy, "An Exact Solution for the Bending of Thin and Thick Cross-Ply Laminated Beams", Computers \& Structures, Vol. 37, pp.195-203 (1997).

[2] S.R. Rao and N. Ganesan, "Dynamic Response of Non-Uniform Composites Beam", J. of Sound and Vibration, pp.563-577 (1997).

[3] V. Yildirm, E. Sancaktar and E. Kiral, " Comparison of the In-Plan Natural Frequencies of Symmetric Cross-Ply Laminated Beams Based On The BernoulliEurler and Timoshenko Beam Theories", J. of Appl. Mech., Vol. 66, pp. 410-417 (1999).

[4] S.M. Nabi and N. Ganesan, "Generalized Element for the Free Vibration Analysis of Composite Beams", Computers \& Structures, Vol. 51, No. 5, pp.607-610 
(1994).

[5] A.M. Farid, M. Adnan Elshafei and S.S. Kousa, "Finite Element Analysis of Compressor Blade under Extension Bending and Torsion Loads, Part I: Isotropic Materials", Proc. of the $12^{\text {th }}$ Int. Conf. on Aerospace and Aviation Technology (ASAT-12), MTC, Cairo (2007).

[6] A.M. Farid, M. Adnan Elshafei and S.S. Kousa, "Finite Element Analysis of Compressor Blade under Extension Bending and Torsion Loads, Part II: Anisotropic Materials, Proc. of the $13^{\text {th }}$ Int. Conf. on Applied Mech. and Mechanical Engineering (AMME-13), MTC, Cairo (2008).

[7] E.A. Armanios and A.M. Badir, "Free Vibration Analysis of the Anisotropic ThinWalled Closed-Section Beams", AIAA J., Vol. 33, No. 10, pp.1905-1910 (1995).

[8] V. Giavotto, M. Borri, P. Mantegazza, G. Ghiringhelli, V. Carmashi, G. Maffioli and F. Mussi, "Anisotropic Beam Theory And Applications", Computers \& Structures, Vol. 16, No. 4, pp. 403-413 (1983).

[9] D. Hagodes, A. Atilgan, M. Fulton and L. Rehfield, "Free Vibration Analysis of Composite Beams", J. of the American Helicopter Society, Vol. 36, No. 3, pp. 3647 (1991).

[10] R. Chandra and I. Chopra, "Experimental and Theoretical Investigation of the Vibration Characteristics of Rotating Composite Box Beams", J. of Aircraft, Vol. 29, No. 4, pp. 657-664 (1992).29, No. 4, 1992, PP. 657-664.

[11] K. Chandrashekhara and K.M. Bangera, "Free Vibration of Composite Beams Using a Refined Shear Flexible Beam Element" Computers and Structures, Vol. 43, No.4, pp.719-727 (1992).

[12] J.N. Reddy, "An Introduction to Nonlinear Finite Element Analysis", Oxford University Press, USA (2004).

[13] J.N. Reddy, 'Mechanics of Laminated Composite Plates and Shells, Theory and Analysis", 2nd edition, CRC Press, USA (2004).

[14] D.H. Allin and W.E. Hasiler, "Int. to Aerospace Structural Analysis", John Weily \& Sons Inc., p.149,154,281,292,295, Printed in USA (1985).

[15] J.N. Reddy, "An introduction of the Finite Element Method", $2^{\text {nd }}$ edition, McGrawHill Inc., p.148, Printed in USA (1993).

[16] D. Gay and S.V. Hoa, ' Composite Materials Design and Applications, 2nd edition', CRC Press, USA (2007).

[17] R.F. Gibson, "Principles of Composite Material Mechanics", McGraw-Hill Inc., pp. 201-207, Printed in USA (1994).

[18] O.C. Zienkiewicz and R.L. Taylor, 'The Finite Element Method $4^{\text {th }}$ edition Volume1: Basic Formulation and Linear Problems', McGraw-Hill book company, Europe, pp.230-242, Printed in USA (1989).

[19] R.D. Cook, D.S. Malkus and M.E. Plesha, "Concept and Applications of Finite

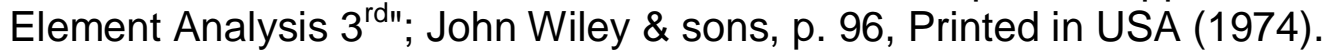

[20] I. Bendary," Finite Element Analysis of Composite Beams with Distributed Piezoelectric Actuators and Sensors", M. Sc. dissertation, MTC, Cairo (2007). 


\section{Appendix A}

The stress-strain relation for a thin orthotropic lamina of an anisotropic beam having coincidence of principal axis on geometric axis is given by [16]:

$$
\begin{aligned}
& \left\{\begin{array}{l}
\sigma_{1} \\
\sigma_{2} \\
\sigma_{6}
\end{array}\right\}=\left[\begin{array}{ccc}
Q_{11} & Q_{12} & 0 \\
Q_{12} & Q_{22} & 0 \\
0 & 0 & Q_{66}
\end{array}\right]\left\{\begin{array}{l}
\varepsilon_{1} \\
\varepsilon_{2} \\
\varepsilon_{6}
\end{array}\right\} \\
& \left\{\begin{array}{l}
\sigma_{4} \\
\sigma_{5}
\end{array}\right\}=\left[\begin{array}{cc}
Q_{44} & 0 \\
0 & Q_{55}
\end{array}\right]\left\{\begin{array}{l}
\varepsilon_{4} \\
\varepsilon_{5}
\end{array}\right\}
\end{aligned}
$$

where, $Q_{i j}$ is the reduced stiffness coefficient.

The components of the lamina stiffness matrix in terms of the engineering constants are given as:

$$
\begin{aligned}
& Q_{11}=\frac{E_{1}}{1-v_{12} v_{21}}, \quad Q_{12}=\frac{v_{12} E_{2}}{1-v_{12} v_{21}}, \quad Q_{66}=G_{12} \\
& Q_{22}=\frac{E_{2}}{1-v_{12} v_{21}}, \quad Q_{44}=G_{23}, \quad Q_{55}=G_{13},
\end{aligned}
$$

where; $E_{1}$ and $E_{2}$ are the Young's modulus in the longitudinal and the transversal directions of the fiber, respectively, and $v_{12}$, and $v_{21}$ are Poisson's ratios in the two directions. The stress-strain relation of a lamina in the geometric directions $x, y$ and $z$ is given by:

$$
\begin{gathered}
\left\{\begin{array}{l}
\sigma_{x x} \\
\sigma_{y y} \\
\sigma_{x y}
\end{array}\right\}=\left[\begin{array}{lll}
\bar{Q}_{11} & \bar{Q}_{12} & \bar{Q}_{16} \\
\bar{Q}_{12} & \bar{Q}_{22} & \bar{Q}_{26} \\
\bar{Q}_{16} & \bar{Q}_{26} & \bar{Q}_{66}
\end{array}\right]\left\{\begin{array}{l}
\varepsilon_{x x} \\
\varepsilon_{y y} \\
\varepsilon_{x y}
\end{array}\right\} \\
\left\{\begin{array}{l}
\sigma_{y z} \\
\sigma_{x z}
\end{array}\right\}=\left[\begin{array}{ll}
\bar{Q}_{44} & \bar{Q}_{45} \\
\bar{Q}_{45} & \bar{Q}_{55}
\end{array}\right]\left\{\begin{array}{l}
\varepsilon_{y z} \\
\varepsilon_{x z}
\end{array}\right\}
\end{gathered}
$$

where; $\bar{Q}_{i j}$ is the transformed reduced stiffness coefficient.

The stress-strain relation of a lamina is rewritten as [17]:

$$
\left\{\begin{array}{l}
\sigma_{x x} \\
\sigma_{x z}
\end{array}\right\}=\left[\begin{array}{ll}
\tilde{Q}_{11} & \\
& \tilde{Q}_{55}
\end{array}\right]\left\{\begin{array}{l}
\varepsilon_{x x} \\
\varepsilon_{x z}
\end{array}\right\}
$$

where, $\tilde{Q}_{i j}$ is the transformed reduced stiffness coefficient and given by: 


$$
\begin{gathered}
\tilde{\mathrm{Q}}_{\mathrm{ij}}=\overline{\mathrm{Q}}_{\mathrm{ij}}-\overline{\mathrm{Q}}_{\mathrm{i} 3} \overline{\mathrm{Q}}_{\mathrm{j} 3} / \overline{\mathrm{Q}}_{33} \quad \text { For } \mathrm{i}, \mathrm{j}=1 \\
\tilde{\mathrm{Q}}_{\mathrm{ij}}=\overline{\mathrm{Q}}_{\mathrm{ij}} \quad \text { For } \mathrm{i}, \mathrm{j}=5
\end{gathered}
$$

\section{Appendix B}

The element stiffness matrix for isotropic Timoshenko Beam is:

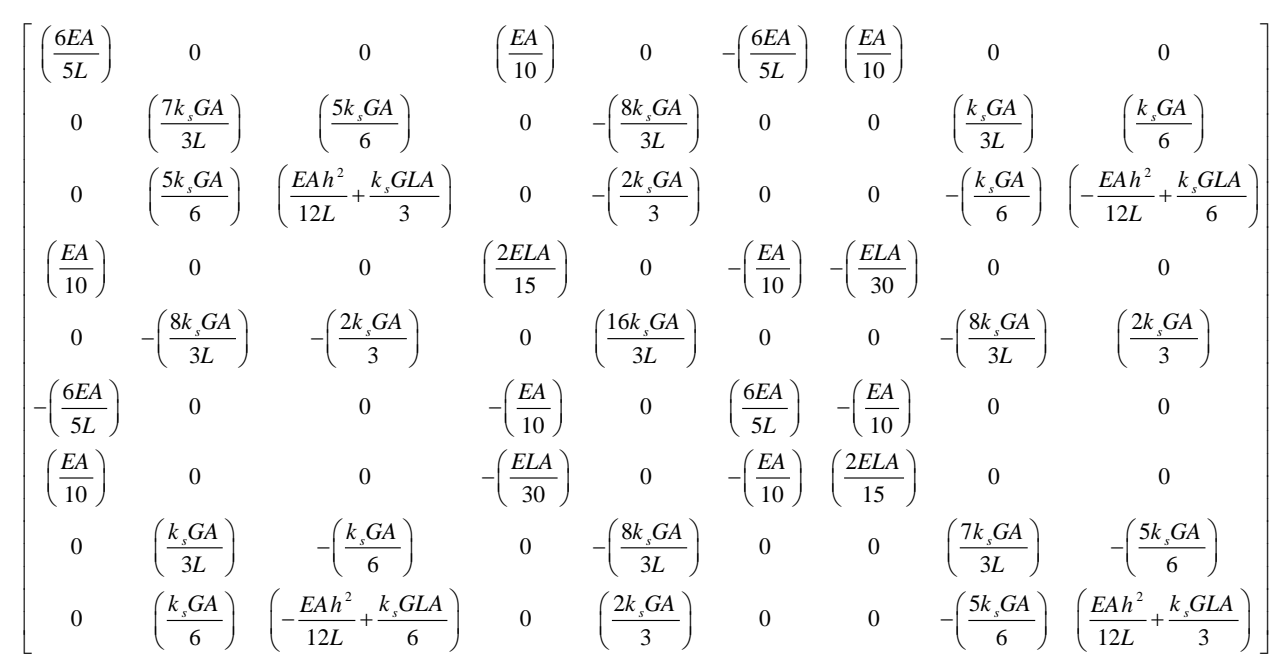

The element load vector:

$$
\begin{aligned}
& F_{\text {element }}^{\prime}=\left[F_{1}+F_{2}\right] \\
& F_{1}=\left[\frac{1}{2}(t L b) \quad \frac{1}{6}\left(f_{t} L b\right) \quad \frac{1}{2}(t z L b) \quad \frac{1}{12}(t L b) \quad \frac{2}{3}\left(f_{t} L b\right)\right] \\
& F_{2}=\left[\frac{1}{2}(t L b)+\left(f_{a} b h\right)-\frac{1}{12}(t L b) \quad \frac{1}{6}\left(f_{t} L b\right) \quad \frac{1}{2}(t z L b)\right]
\end{aligned}
$$

The element stiffness matrix for Anisotropic Timoshenko Beam:

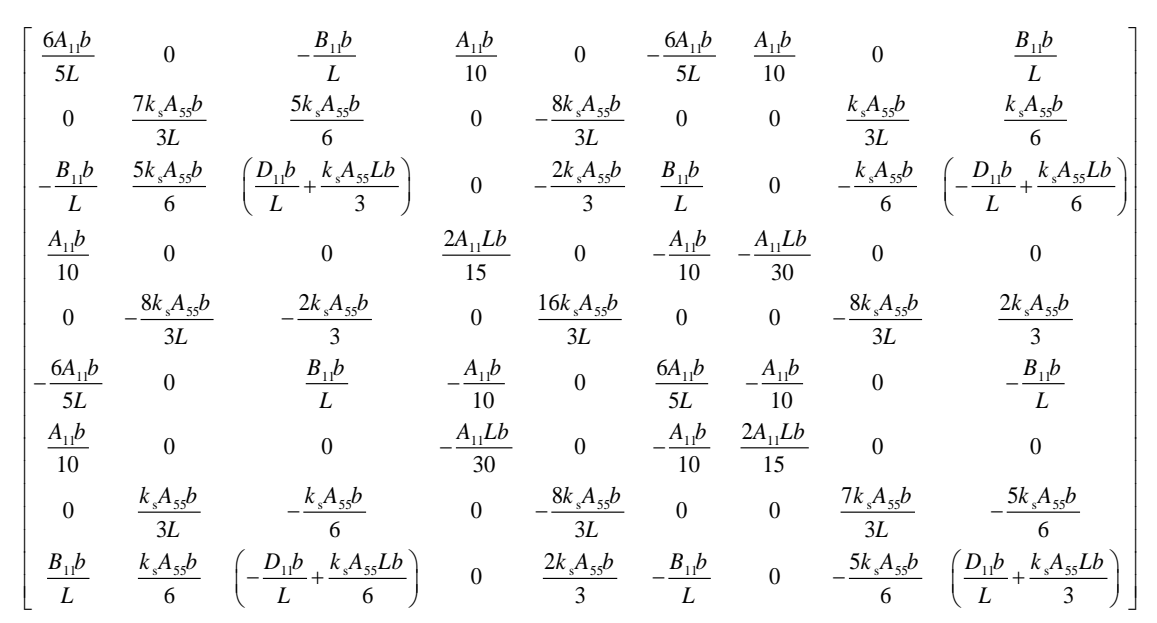

The element mass matrix for the Timoshenko Beam: 


\begin{tabular}{|c|c|c|c|c|c|c|c|c|}
\hline$\left(\frac{13\left(I_{L} L\right)}{35}\right)$ & 0 & $\left(\frac{7\left(I_{1} L\right)}{20}\right)$ & $\left(\frac{11\left(I_{\circ} L\right)}{210}\right)$ & 0 & $\left(\frac{9\left(I_{\circ} L\right)}{70}\right)$ & $-\left(\frac{13\left(I_{L} L\right)}{420}\right.$ & 0 & $\left(\frac{3(I, L)}{20}\right)$ \\
\hline 0 & $\left(\frac{2\left(I_{0} L\right)}{15}\right)$ & 0 & 0 & $\left(\frac{\left(I_{\circ} L\right)}{15}\right)$ & 0 & 0 & $-\left(\frac{\left(I_{\circ} L\right)}{30}\right)$ & 0 \\
\hline$\left(\frac{7\left(I_{1} L\right)}{20}\right)$ & 0 & $\left(\frac{\left(I_{2} L\right)}{3}\right)$ & $\left(\frac{\left(I_{1} L\right)}{20}\right)$ & 0 & $\left(\frac{3\left(I_{1} L\right)}{20}\right)$ & $-\left(\frac{\left(I_{1} L\right)}{30}\right)$ & $o$ & $\left(\frac{\left(I_{2} L\right)}{6}\right)$ \\
\hline$\left(\frac{11\left(I_{L} L\right)}{210}\right)$ & 0 & $\left(\frac{\left(I_{1} L\right)}{20}\right)$ & $\left(\frac{\left(I_{\circ} L\right)}{105}\right)$ & 0 & $\left(\frac{13\left(I_{o} L\right)}{420}\right)$ & $-\left(\frac{\left(I_{0} L\right)}{140}\right)$ & 0 & $\left(\frac{\left(I_{1} L\right)}{30}\right)$ \\
\hline 0 & $\left(\frac{\left(I_{0} L\right)}{15}\right)$ & 0 & 0 & $\left(\frac{8\left(I_{\circ} L\right)}{15}\right)$ & 0 & 0 & $\left(\frac{\left(I_{\circ} L\right)}{15}\right)$ & 0 \\
\hline$\left(\frac{9\left(I_{\mathrm{o}} L\right)}{70}\right)$ & 0 & $\left(\frac{3\left(I_{1} L\right)}{20}\right)$ & $\left(\frac{13\left(I_{\circ} L\right)}{420}\right)$ & 0 & $\left(\frac{13\left(I_{\circ} L\right)}{35}\right)$ & $\left(\frac{11\left(I_{\circ} L\right)}{210}\right)$ & 0 & $\left(\frac{7(I, L)}{20}\right)$ \\
\hline$=\left(\frac{13\left(I_{\circ} L\right)}{420}\right)$ & 0 & $-\left(\frac{\left(I_{1} L\right)}{30}\right)$ & $-\left(\frac{\left(I_{\circ} L\right)}{140}\right)$ & 0 & $-\left(\frac{11\left(I_{\circ} L\right)}{210}\right.$ & $\left(\frac{I_{0} L}{105}\right)$ & 0 & $-\left(\frac{\left(I_{1} L\right)}{20}\right)$ \\
\hline 0 & $-\left(\frac{(I, L)}{30}\right)$ & 0 & 0 & $\left(\frac{I_{o} L}{105}\right)$ & 0 & 0 & $\left(\frac{2\left(I_{\circ} L\right)}{15}\right)$ & 0 \\
\hline$\left(\frac{3\left(I_{1} L\right)}{20}\right)$ & 0 & $\left(\frac{\left(I_{2} L\right)}{6}\right)$ & $\left(\frac{\left(I_{1} L\right)}{30}\right)$ & 0 & $\left(\frac{7\left(I_{1} L\right)}{20}\right)$ & $-\left(\frac{\left(I_{1} L\right)}{20}\right)$ & 0 & $\left(\frac{\left(I_{2} L\right)}{3}\right)$ \\
\hline
\end{tabular}

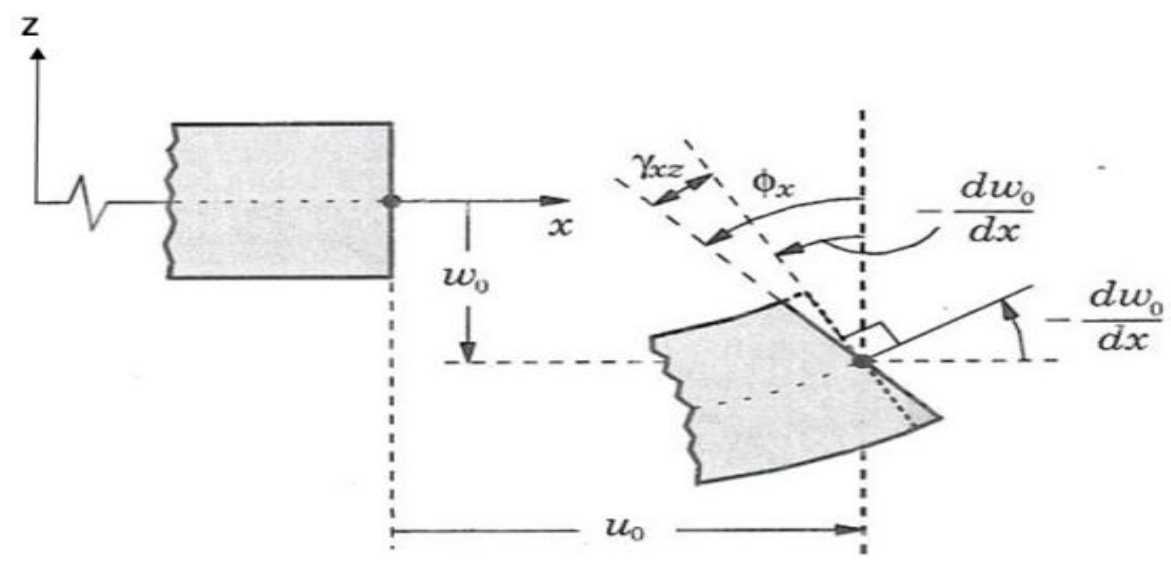

Fig.1. Deformed and un-deformed shape of Timoshenko beam [12].

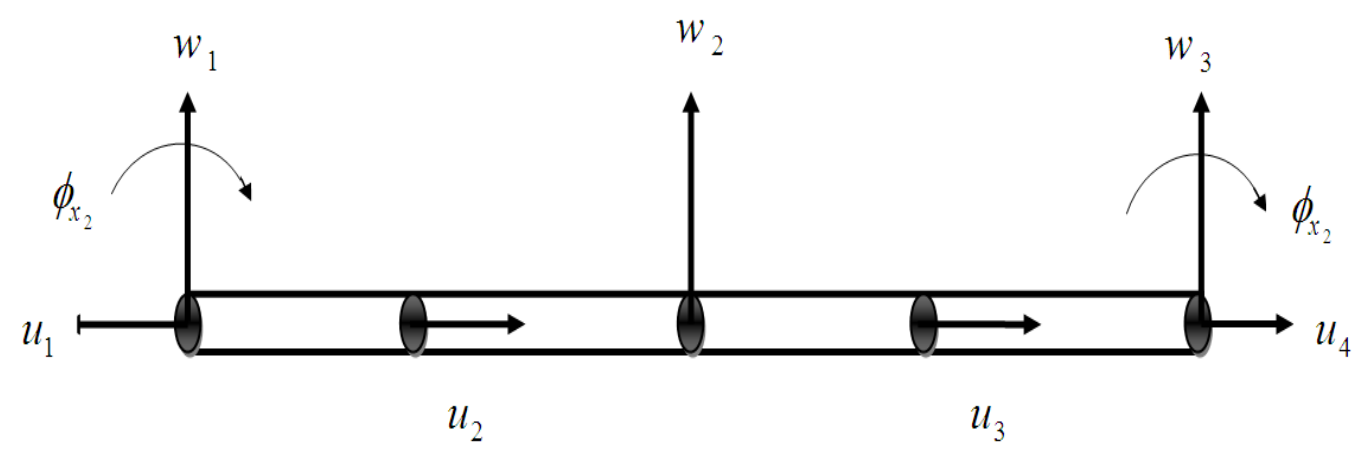

Fig. 2. Nodal degrees of freedom for higher order element. 


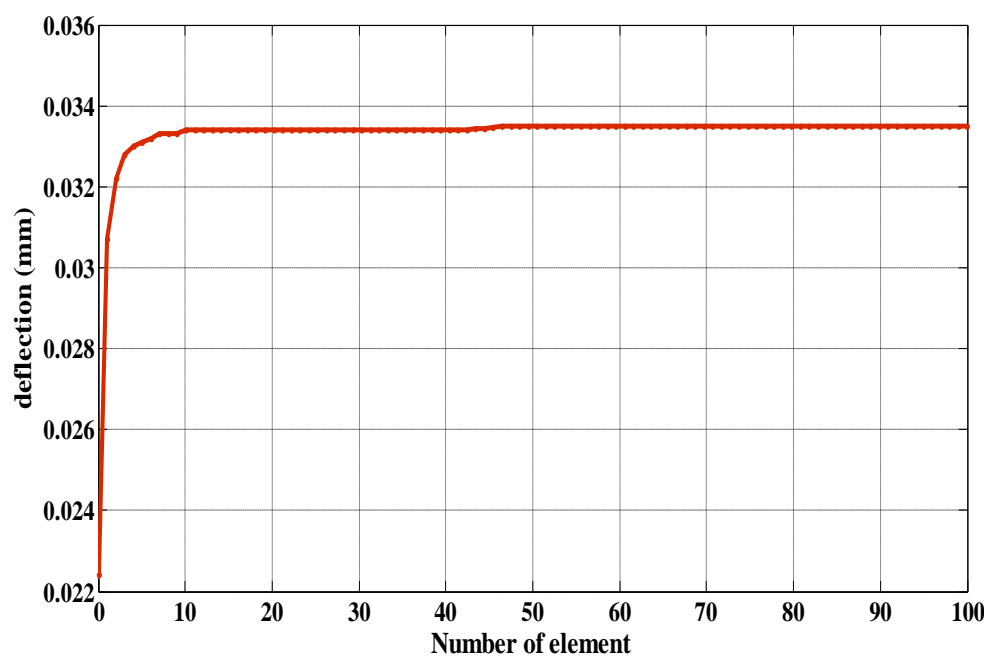

Fig. 3. Transversal tip displacement vs. number of elements.

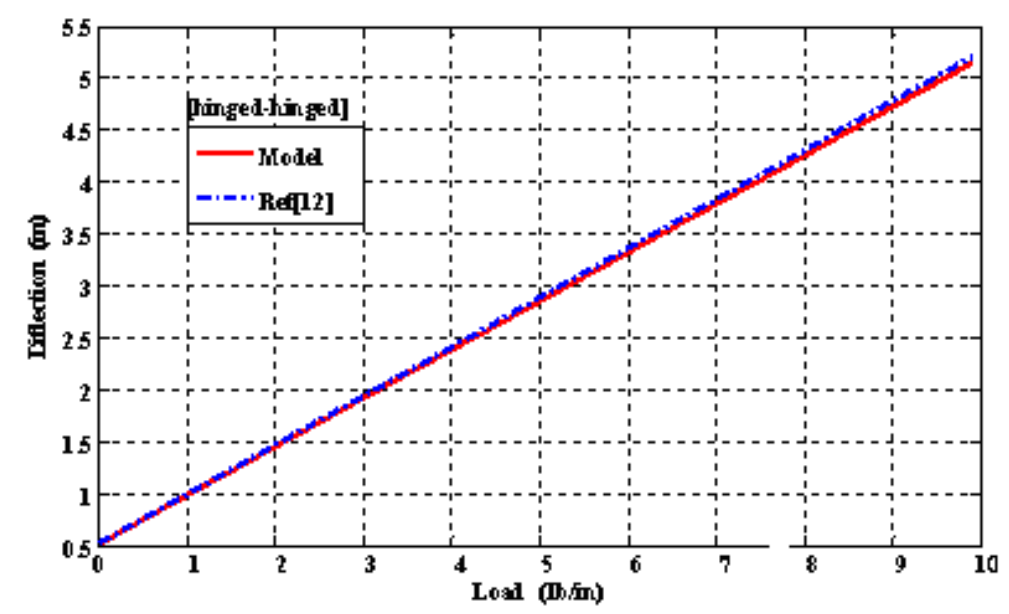

Fig. 4. Comparison of the deflection of the present model and the exact solution for a simply supported beam.

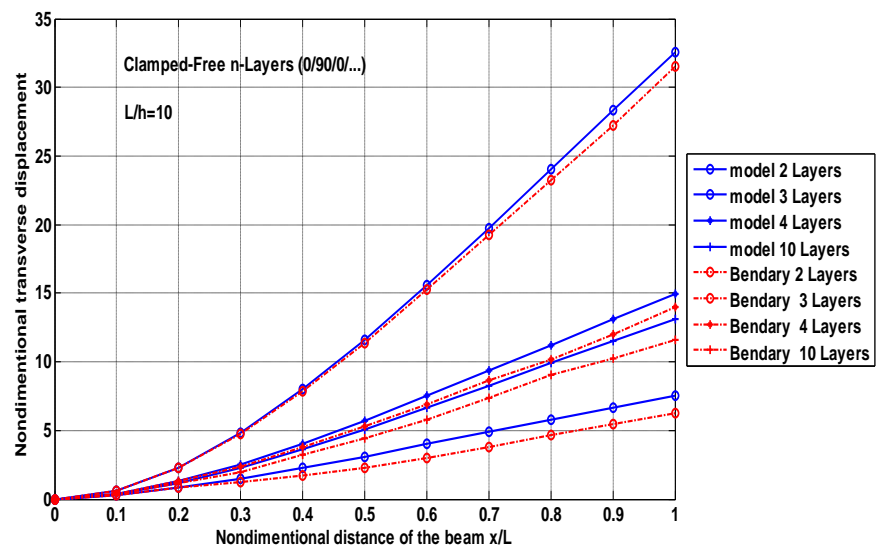

Fig. 5. Non-dimensional transversal deflection vs. non dimensional distance along the beam length $(L / h=10)$. 


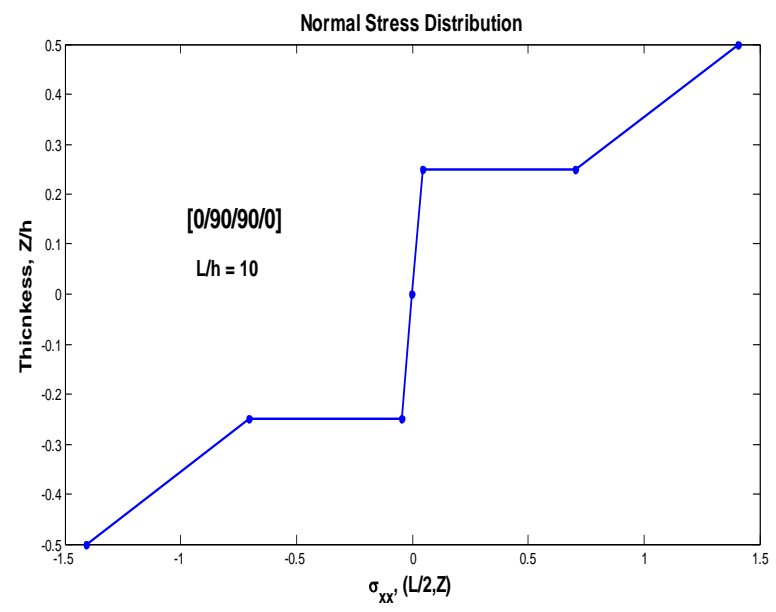

Fig. 6. Normal stress distribution for a composite laminate $\left(0^{\circ} / 90^{\circ} / 90^{\circ} / 0^{\circ}\right)$.

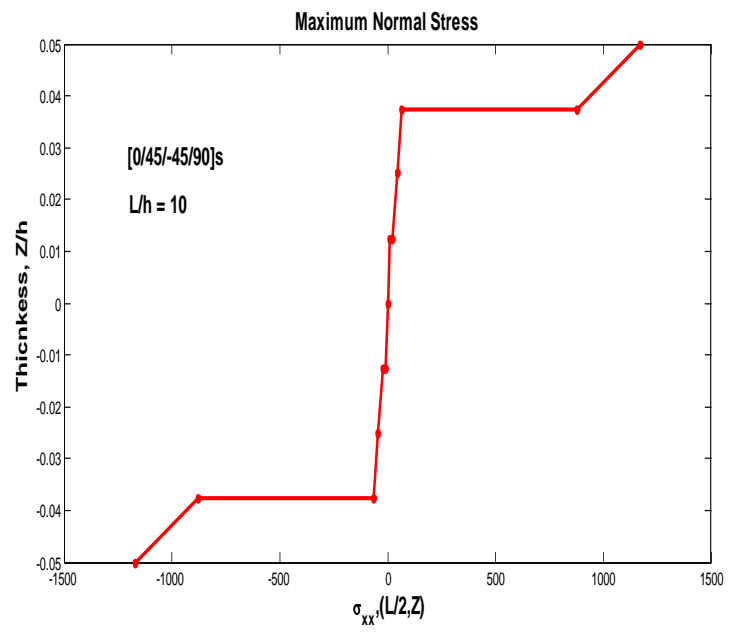

Fig. 7. Normal stress distribution for a composite

laminate $\left(0^{\circ} / 45^{\circ} /-45^{\circ} /, 90^{\circ} / 90^{\circ} /-45^{\circ} / 45^{\circ} / 0^{\circ}\right)$

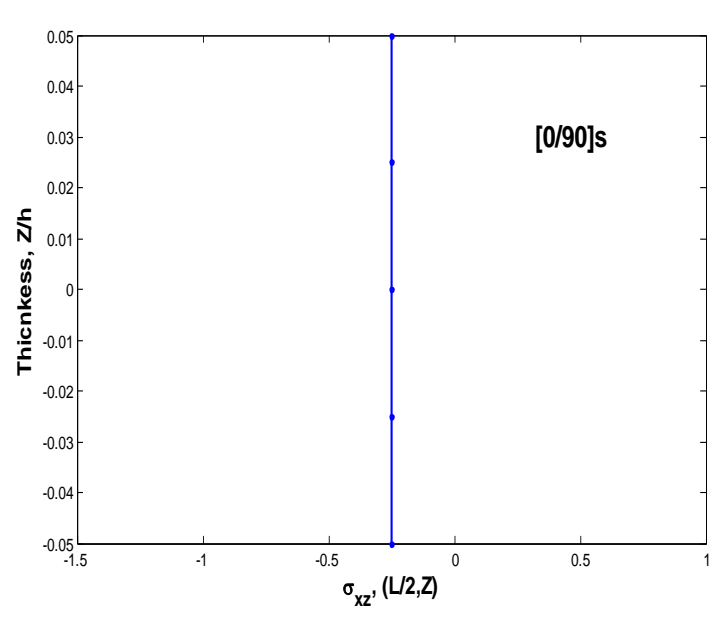

Fig. 8. Shear stress for a composite laminate $\left(0^{\circ} / 90^{\circ} / 90^{\circ} / 0^{\circ}\right)$. 


\section{NOMENCLATURE}

\begin{tabular}{|c|c|}
\hline Symbols & definition \\
\hline$[M]$ & Mass matrix of the beam element in stretching. \\
\hline$[K]$ & Element stiffness matrix. \\
\hline$\{F\}$ & Element nodal forces. \\
\hline$q$ & Nodal displacement. \\
\hline$\ddot{q}$ & The second derivative of the nodal displacement. \\
\hline$\Pi$ & Total potential energy. \\
\hline $\mathrm{U}$ & Internal strain energy. \\
\hline$W$ & Work done by external loads. \\
\hline$u$ & Displacement of any point in the $x$-direction. \\
\hline$w$ & Displacement of any point in the z-direction. \\
\hline$\phi_{x}$ & Angle of rotation. \\
\hline$u^{\circ}$ & Reference surface displacement along $x$-axis. \\
\hline$w^{\circ}$ & Reference surface displacement along z-axis. \\
\hline$\varepsilon_{x}$ & Linear strain in the $x$-direction. \\
\hline$\varepsilon_{y}$ & Linear strain in the y-direction. \\
\hline$\varepsilon_{z}$ & Linear strain in the z-direction. \\
\hline$\varepsilon^{2}{ }_{x}^{2}$ & Reference surface extensional strain in the x-direction. \\
\hline$\varepsilon_{y}^{0}$ & Reference surface extensional strain in the $y$-direction. \\
\hline$\gamma_{x y}^{\circ}$ & In-plane shear strain. \\
\hline$\kappa_{x}^{\circ}$ & Reference surface curvature in the $x$-direction. \\
\hline$\gamma_{x z}$ & Transversal shear strain in $x-z$ plane. \\
\hline $\mathrm{n}$ & Layer number in the beam. \\
\hline$N$ & Total number layers in the beam. \\
\hline$A$ & Beam cross section area. \\
\hline$\sigma_{x}$ & Normal stress in the $x$-direction. \\
\hline E & Young's modulus. \\
\hline$c_{1}, c_{2}, c_{3}$ and $c_{4}$ & Constant values. \\
\hline$u_{1}, u_{2}, u_{3}$ and $u_{4}$ & Axial displacements at the boundaries of beam element. \\
\hline$w_{1}, w_{2}$, and $w_{3}$ & Transversal displacements at the boundaries of beam element. \\
\hline$\phi_{1}$ and $\phi_{2}$ & Rotation angles. \\
\hline$F_{\text {element }}$ & Element load vector. \\
\hline$L$ & Length of beam element. \\
\hline$b$ & Width of beam element. \\
\hline$h$ & Height of beam element. \\
\hline$T_{k}$ & Kinetic energy. \\
\hline$\rho$ & Mass density of material. \\
\hline$\xi_{i}$ & Axial displacement shape function. \\
\hline$\zeta_{i}$ & Transversal displacement shape function. \\
\hline
\end{tabular}




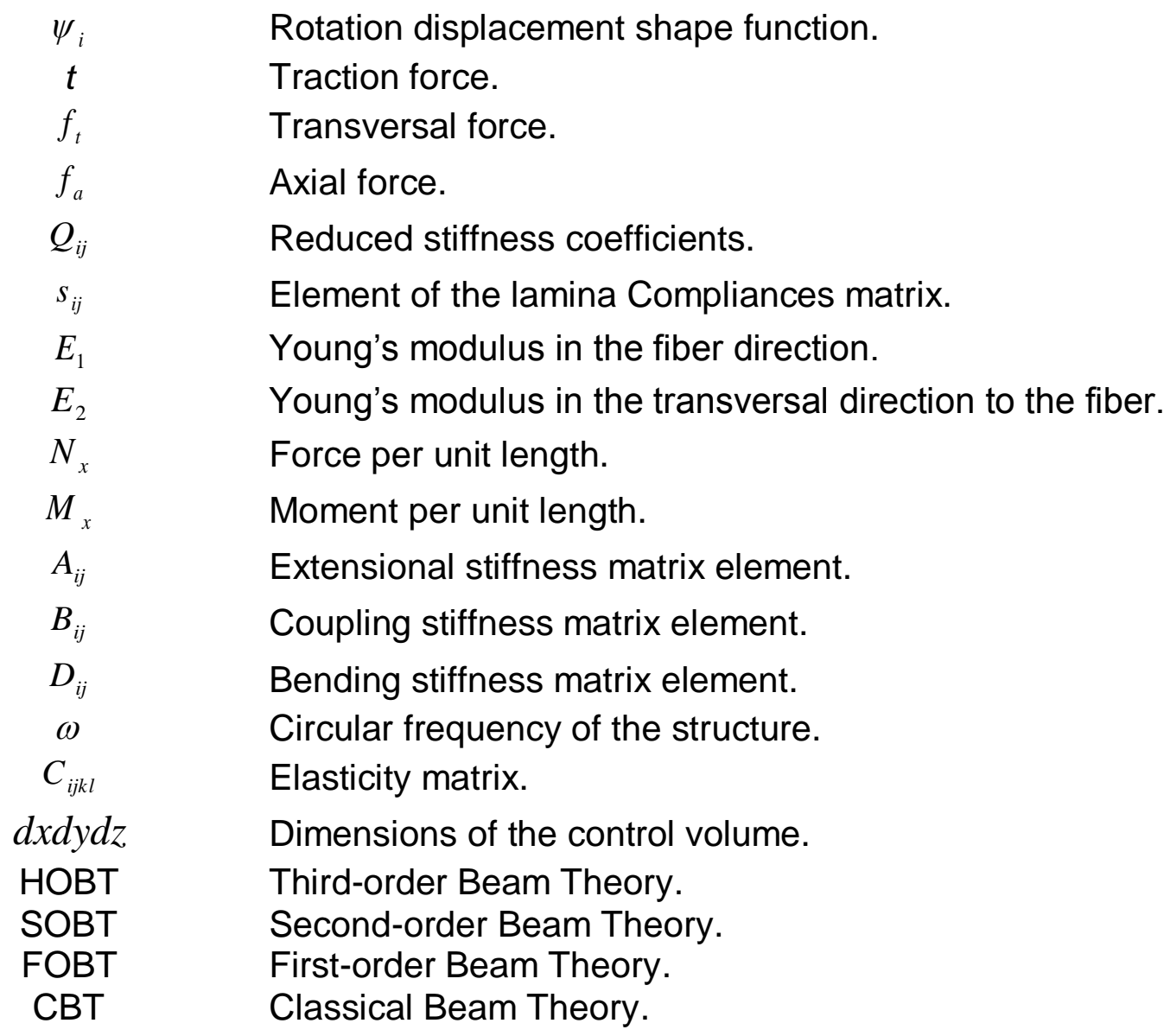

